\title{
Zika Virus: A Basic Overview of an Emerging Arboviral Infection in the Western Hemisphere
}

\author{
Kelly G. Vest, DVM, MPH, DrPH
}

\section{ABSTRACT}

Since February 2015, Zika virus has spread throughout the Western Hemisphere, starting in Brazil. As of March 2016, autochthonous transmission has been reported in at least 31 countries or territories. For countries in the Americas, the spread of Zika virus, a previously unfamiliar disease, follows similar emerging infection introductions of West Nile virus and Chikungunya virus and their spread throughout the American continents and the Caribbean nations. The Pan American Health Organization and the World Health Organization have issued alerts and a Public Health Emergency of International Concern announcement related to the recent cluster of microcephaly cases and other neurological disorders in Brazil that are temporally associated with Zika virus, which highlights the possible adverse impact of viral infection. This article provides an overview of the Zika virus infection and presents the historical background of the virus, a description of the pathogen, the epidemiology and clinical spectrum of Zika virus infection, diagnosis and treatment approaches, and prevention and control measures. Understanding what is known about the virus and its clinical presentation will assist in prevention, detection, and response measures to reduce and control the spread of the virus throughout the Western Hemisphere. (Disaster Med Public Health Preparedness. 2016;10:707-712)

Key Words: Zika virus, arbovirus, epidemic

$\mathrm{I}$ n May 2015, the Pan American Health Organization issued an Epidemiological Alert recommending that Member States establish and maintain the capacity to detect and clinically manage Zika virus (ZIKV) infections and control the disease vector. ${ }^{1}$ This alert was based on the possible outbreak of ZIKV cases in the northeastern states of Brazil since February 2015. ${ }^{2}$ As of March 2016, local ZIKV transmission has been reported in at least 31 countries or territories in the Western Hemisphere. $^{3}$ On 1 February 2016, the Director-General of the World Health Organization issued a Public Health Emergency of International Concern announcement related to the recent cluster of microcephaly cases and other neurological disorders in Brazil and following similar reports from the 2014 French Polynesian outbreak as these are temporally associated with ZIKV. ${ }^{4}$

In 1992, the Institute of Medicine issued a report defining emerging infections as newly recognized agents, as agents or diseases occurring in new hosts, as previously controlled agents reappearing in endemic areas or agents occurring in new geographic areas, or as changes in agent characteristics such as antimicrobial attributes. ${ }^{5}$ Since 1992, various diseases have "emerged" and are globally familiar. Such infections include avian influenza H5N1, Hendra virus, Nipah virus, West Nile virus, severe acute respiratory syndrome coronavirus, and more recently Middle East respiratory syndrome coronavirus, Chikungunya virus, and Ebola virus.
The recent ZIKV outbreak fits into these emerging infection models because it was first identified in Africa in 1947 and remained relatively unknown with sporadic cases in Africa and Asia until outbreaks in 2007 and 2013 occurring in Micronesia and French Polynesia, respectively. Even so, ZIKV remained an unfamiliar disease globally among the health community and unknown to the public until 2015. This article provides an overview of ZIKV, including a historical background of the virus, a description of the pathogen, the epidemiology of infection, the clinical spectrum of illness, diagnostic and treatment approaches, and prevention and control measures.

\section{HISTORICAL BACKGROUND}

The ZIKV is named for the Zika Forest in Uganda where the first virus was identified in a rhesus monkey that was used as a sentinel animal in a yellow fever study in April 1947. ${ }^{6}$ During the same time period, additional studies showed that mosquitoes (Aedes africanus) carried the ZIKV. From the 1960s until 2007, various cases and serologic studies identified ZIKV-positive individuals, animals, and mosquitoes from several countries in Africa and South Asia. In April 2007, a ZIKV outbreak occurred on Yap Island of the Federated States of Micronesia where 49 confirmed and an additional 59 probable cases were identified. ${ }^{7}$ Then in October 2013 to February 2014, a large outbreak began among the islands of French 
Polynesia, where over 19,000 suspected cases are estimated to have occurred. ${ }^{8}$

In February 2015, an outbreak of a dengue-like syndrome was reported in the northeastern states of Brazil. The illness demonstrated primarily as a rash illness and pruritus with low-grade fever or no fever, with or without headache, pain or swelling in the joints, and muscle and eye pain. ${ }^{2} \mathrm{~A}$ small percentage $(13 \%)$ of cases tested positive for dengue fever; most were negative for other illnesses including measles, rubella, and chikungunya. In April 2015, ZIKV was identified by reverse transcriptase polymerase chain reaction (RT-PCR) and by September 2015, the Ministry of Health reported an increased number of babies with microcephaly from the outbreak areas among an estimated 400,000 to 1.3 million suspected human cases. This report of microcephaly gave greater weight and additional attention to ZIKV and the spread of the virus throughout the Western Hemisphere. ${ }^{9}$ As of 4 March 2016, more ZIKV cases have been reported from 31 countries or territories in the Western Hemisphere.

\section{DESCRIPTION OF THE PATHOGEN}

The pathogen, ZIKV, is a single-stranded RNA virus found within the Flaviviridae family and Flavivirus genus. ${ }^{10} \mathrm{Within}$ this same genus and family are other arboviruses including yellow fever, dengue, West Nile, and Japanese encephalitis virus. ${ }^{11}$ The ZIKV is divided into 2 genetic lineages, an African lineage and an Asian lineage. These lineages are historically associated with the geography for which they are named. As for the virus that is spreading within the Western Hemisphere, recent genetic sequencing and comparisons of viruses collected from autochthonous cases in Suriname in November 2015 were reported genetically similar to the Asian lineage viruses. ${ }^{12}$ The virus is susceptible to and killed by potassium permanganate, ether, and temperatures above $60^{\circ} \mathrm{C}$. Use of $10 \%$ ethanol is reported to be ineffective to kill or inactivate the virus. ${ }^{13}$

\section{PATHOGENESIS}

Little is known about the pathology of the ZIKV. A 2015 study showed that ZIKV is injected by the mosquito vector in the skin and skin immune cells, including dermal fibroblasts, epidermal keratinocytes, and immature dendritic cells. The virus replicates, leading to activation of an antiviral innate immune response and type I interferons in the cells. ${ }^{14}$ Viral replication occurs in cellular cytoplasm or in the infected cell nuclei. It is theorized that the virus spreads in the bloodstream to the lymph nodes. A recent study reported that ZIKV directly infects human cortical neural progenitor cells, resulting in stunted growth and cell death, which suggests that ZIKV may impact human brain development. ${ }^{15}$ An additional report detected ZIKV in brain tissues of infants with microcephaly and in placental tissues from early miscarriages. ${ }^{16}$ Detection of ZIKV in the blood has been reported to occur as early as illness onset and to continue up to 11 days after onset. ${ }^{13}$ The virus has been detected in blood, urine, semen, amniotic fluid, breast milk, and cerebrospinal fluid.

\section{EPIDEMIOLOGY}

Since the discovery of the virus in the sentinel rhesus monkey in 1947, no definite animal reservoir has been identified for ZIKV. Yet, mice are susceptible to infection when injected with the virus. ${ }^{6}$ Early surveys of nonprimate animals, to include small mammals in endemic areas where mosquitoes tested positive for the virus, found no evidence of infection. ${ }^{17}$ Antibodies to ZIKV have been found in nonhuman primates, small ruminants, and rodents. ${ }^{13,18,19}$ It is suspected that nonhuman primates serve as an animal reservoir with humans acting as a transmission vessel, but more needs to be studied on the subject. The insect reservoir is the Aedes spp. mosquito. It is a container-breeding mosquito that tends to feed during the day and that has become well adapted to urban and peri-urban environments.

\section{Geographic Distribution}

Since the discovery of the virus in Uganda, the African countries have been the focus of where the disease is endemic. Human case reports have been published for Nigeria, with serologic evidence of human infection reported in the African countries of Central African Republic, Egypt, Gabon, Senegal, Sierra Leone, Tanzania, and Uganda, and in the Asian countries of Cambodia, India, Indonesia, Malaysia, Pakistan, Philippines, Thailand, and Vietnam. Similarly, the virus has been isolated from vectors in many of these countries to include Cote d'Ivoire. ${ }^{13}$ In 2007, ZIKV was identified in human cases on Yap Island, Micronesia, and in October 2013 in French Polynesia. ${ }^{8}$

Since May 2015, local transmission has been reported in 31 countries or territories in the Western Hemisphere. With the present outbreak of disease, further spread of the disease is likely and has been compared to the spread of chikungunya and the occurrence of dengue in the Western Hemisphere, as they share the same vectors. ${ }^{20}$ Autochthonous transmission has not been reported within the United States, yet travelers from the United States have returned from areas of known disease transmission with the disease.

\section{Incidence and Prevalence}

Reported incidence and prevalence levels of ZIKV are scarce. Historical documents have noted studies conducted in Nigeria in the 1960 s and 1970 s that identified up to $40 \%$ of persons testing seropositive with neutralizing antibody. Other limited studies show serologic evidence in other African countries and also in parts of South Asia. ${ }^{13}$

During the 2007 ZIKV outbreak on Yap Island, Micronesia, an estimated $73 \%$ of the population aged 3 years and older 
had been infected with the virus. ${ }^{7}$ In a seroprevalence study in 2013 prior to the French Polynesian outbreak, $0.8 \%$ of blood donors tested were seropositive for ZIKV. ${ }^{21}$ Additionally, $3 \%$ of asymptomatic blood donors tested by RT-PCR during the French Polynesian outbreak period were positive. ${ }^{22}$ With the ongoing outbreak in Brazil, the Brazilian Ministry of Health estimates up to 1.3 million suspected cases during 2015.

It remains to be determined whether ZIKV infection will become prevalent in the Western Hemisphere. However, if ZIKV infections follow the same pattern as other introduced arboviruses such as West Nile virus and Chikungunya virus, there will be an acute increase in disease cases followed by a decrease and plateauing of incident cases. ${ }^{23}$

\section{Transmission}

The primary mode of transmission of the virus is by the bite of a vector mosquito. The Aedes spp. mosquitoes have been identified as having the ability to transmit the virus for up to 60 days. For the Western Hemisphere, Aedes aegypti and Aedes albopictus are common vectors. Within these mosquitoes, from the time a blood meal is taken, the incubation period until a mosquito is infective is from 5 to 10 days. ${ }^{13,24,25}$

There is evidence of perinatal and in utero transmission reported from earlier outbreaks, ${ }^{26}$ and the suspected association of microcephaly as well as the identification of ZIKV in amniotic fluid suggests transmission between mother and fetus. Owing to these perinatal viral exposures and possible adverse fetal outcomes, pregnant women and women of child-bearing age are considered high-risk populations. ${ }^{3,9}$ A recent report found infective ZIKV particles in breast milk from a mother postpartum, which suggests breast milk as a possible source of infection, although her baby remained healthy. ${ }^{27}$

To date, 3 reports have suggested that ZIKV transmission by sexual contact is possible. ${ }^{28,29}$ In one case, a male working in Senegal returned to the United States and became ill 6 days after return. His spouse also became ill 4 days after he had become ill. Both had had sexual contact prior to any clinical symptoms developing. ${ }^{30}$ A second case was reported in which ZIKV was isolated from semen. ${ }^{31}$ In a third case a patient had sexual contact with a returning male traveler. ${ }^{29,32}$ Reports suggest that ZIKV may be detectable in semen from 2 to 10 weeks after illness onset. ${ }^{33}$ Sexual transmission from infected women to sex partners is unknown and not reported.

The spread of ZIKV through blood transfusion appears plausible and recent reports and investigations are ongoing to describe ZIKV transmission via transfusion. On 7 February 2016, the Brazilian Ministry of Health reported 2 possible ZIKV cases of blood transfusion transmission from $2015 .{ }^{34}$ Transfusion risk due to ZIKV is unclear. During the French Polynesian outbreak, 2.8\% of blood donors tested positive for Zika RNA, which suggests that transfusion transmission is possible. As of 1 February 2016, the American Association of Blood Banks released recommendations to reduce the risk of transfusion transmission. By recommendation of the American Association of Blood Banks, blood donors who have traveled to Mexico, the Caribbean, or Central or South America during the 28 days before donation should not donate. ${ }^{35}$ Presently, there are no licensed blood donor screening tests in the United States to identify Zika RNA.

\section{CLINICAL SPECTRUM}

Zika virus infection symptoms have been described as a dengue-like illness. ${ }^{8}$ Many infected individuals will be asymptomatic and an estimated 1 in 5 infected with ZIKV will become symptomatic. Characteristic clinical findings include acute onset of fever, maculopapular rash, arthralgia (wrist, fingers, and ankles), and conjunctivitis. ${ }^{36}$ Other symptoms include asthenia, malaise, chills, headache, photophobia, muscle pain, aphthous ulcers, and prostatitis. Other complications include immune thrombocytopenic purpura and hematospermia. ${ }^{30,31}$ Clinical illness usually is mild with symptoms lasting for several days to a week. Severe disease requiring hospitalization is uncommon and fatalities are rare.

Other adverse outcomes of ZIKV infection may include neurological syndromes including Guillain-Barre Syndrome, 37-39 acute myelitis, ${ }^{40}$ and meningo-encephalitis. ${ }^{3}$ More recently, another suspected neurologic defect is the temporal association with microcephaly where congenital infections with ZIKV are suggestive of a relationship. Additional reports have presented further evidence linking ZIKV infection during the first trimester of pregnancy with increased birth prevalence of microcephaly. ${ }^{41,42}$ Connected to microcephalic infants are reported ocular manifestations of ZIKV infection including macular atrophy, focal pigment mottling, and chorioretinal atrophy. ${ }^{43-45}$ It is not known what other factors may increase the risk of microcephaly to the fetus. ${ }^{9}$ Other grave fetal outcomes reported include fetal death, placental insufficiency, fetal growth restriction, and CNS injury. ${ }^{41,46}$

\section{DIAGNOSTIC AND TREATMENT APPROACHES}

According to the Centers for Disease Control and Prevention (CDC), preliminary diagnosis of acute ZIKV disease is based on the patient's clinical features, places and dates of travel, and activities. The case definition includes acute onset of fever with maculopapular rash, arthralgia, or conjunctivitis in travelers who have returned from areas with virus transmission within 2 weeks of symptom onset. Dengue and chikungunya infections should be considered in the differential diagnosis and as possible co-infections in the same patients. $^{47}$

Laboratory criteria for diagnosis include isolation of virus from, or demonstration of specific viral antigen or nucleic acid in, tissue, blood, cerebrospinal fluid, or other body fluid, or a 
fourfold or greater change in virus-specific quantitative antibody titers in paired sera, or virus-specific immunoglobulin M (IgM) antibodies in serum with confirmatory virus-specific neutralizing antibodies in the same or a later specimen, or virus-specific IgM antibodies in cerebrospinal fluid or serum. ${ }^{47}$

For acute specimens, during the first 7 days after onset of symptoms, ZIKV disease can often be diagnosed by performing RT-PCR on serum. A negative RT-PCR result does not exclude infection and serologic testing should be performed. ${ }^{48}$ ZIKV-specific IgM and neutralizing antibodies should be performed on specimens collected after 4 days of illness onset. Both acute and convalescent sera should be submitted. Zika virus IgM antibody assays may cross-react with related flaviviruses (eg, dengue and yellow fever viruses). Plaquereduction neutralization testing can be performed to measure virus-specific neutralizing antibodies and discriminate between cross-reacting antibodies in primary flavivirus infections. ${ }^{49}$

For convalescent specimens, IgM antibodies typically persist for approximately 2 to 12 weeks. In patients with a compatible clinical syndrome, serum collected as early as 4 days after illness onset can be tested by Zika, Chikungunya, and dengue virus-specific IgM ELISA (enzyme-linked immunosorbent assay) and positive results confirmed by testing for neutralizing antibodies. ${ }^{48}$

\section{Testing Pregnant Women}

For asymptomatic pregnant women who have traveled to areas with ZIKV transmission, testing can be offered 2 to 12 weeks after pregnant women return from travel..$^{50}$ For asymptomatic pregnant women who reside in areas of ongoing disease transmission, IgM testing is recommended at the initiation of prenatal care with follow-up testing mid-second trimester. For symptomatic pregnant women, testing is recommended during the first week of illness. ZIKV testing of maternal serum includes RT-PCR and IgM and plaque reduction neutralizing antibody testing on specimens collected at 4 or more days after onset of symptoms. ${ }^{50}$

\section{Treatment}

No antiviral treatment or vaccine is currently available for ZIKV infection. Treatment is generally supportive and can include rest, fluids, and use of analgesics and antipyretics. However, owing to the possibility of co-infections with dengue virus, aspirin and other nonsteroidal anti-inflammatory drugs should be avoided until dengue can be ruled out. ${ }^{51}$

\section{PREVENTION AND CONTROL}

As of 21 January 2016, CDC added ZIKV infection to the National Notifiable Disease Surveillance System (event code 11726). ${ }^{47}$ Cases of ZIKV disease should be reported to the state and local health departments per local civilian reporting requirements. Rapid and timely reporting and sharing of information (clinical, virologic, and epidemiologic) relevant to ZIKV infections will assist in the prevention, detection, and response activities. ${ }^{3,4}$

Prevention relies on effective mosquito control and avoidance of vectors. Personal protection recommendations include the use of insect repellent containing Environmental Protection Agency-registered repellents, such as DEET or picaridin; the wearing of long sleeves and long pants treated with permethrin for added protection; and limiting outdoor activities in order to prevent mosquito bites. Additional measures include staying in places with air conditioning or that use window and door screens to keep mosquitoes outside and sleeping under a mosquito bed net if overseas or outside. ${ }^{52}$

Infected individuals should take added precautions to avoid mosquito bites during the first week of illness. Men who reside in or travel to areas of active ZIKV transmission should abstain from sexual activity with pregnant and nonpregnant partners. Furthermore, the consistent and correct use of condoms during sex may reduce risk of transmission. ${ }^{29,50}$

\section{CONCLUSION}

Many things are still not understood about the ZIKV. The experience of the United States with other arboviral infections such as West Nile virus, dengue virus, and more recently with Chikungunya virus provides an example and foreshadowing of what can occur if ZIKV becomes endemic in the Western Hemisphere. ${ }^{23}$ Understanding what is known about the virus and the clinical presentation will assist in prevention, detection, and response measures to reduce and control the spread of the virus throughout the Western Hemisphere.

\section{About the Author \\ Center for Global Health Engagement, Uniformed Services University of the Health Sciences, Rockville, Maryland. \\ Correspondence and reprint requests to Kelly G. Vest, DVM, MPH, DrPH, Science Director, Center for Global Health Engagement, Uniformed Services University of the Health Sciences, 11300 Rockville Pike, Suite 707, Rockville, MD 20852 (e-mail: kvest@cdham.org).}

\section{Disclaimer}

The views expressed in this article are those of the author and do not reflect the official policy or position of the Uniformed Services University of the Health Sciences, Department of Defense, or the US government. The author declares no competing interests.

Published online: March 29, 2016.

\section{REFERENCES}

1. Pan American Health Organization. Epidemiological Alert - Zika Virus Infection. 7 May 2015. http://www.paho.org/hq/index.php?option=com_ docman\&task $=$ doc_view\&Itemid $=270$ \&gid $=30075 \&$ lang=en. Published May 7, 2015. Accessed February 10, 2016. 
2. International Society for Infectious Diseases. Undiagnosed Illness - Brazil: (Northeast, Rio de Janeiro) Zika Virus Suspected. http://www.promedmail. org/post/20150501.3334749. Published May 1, 2015. Accessed February 10, 2016.

3. World Health Organization. Zika Situation Report - Neurological Syndrome and Congenital Anomalies. 4 March 2016. WHO website. http://www.who.int/emergencies/zika-virus/situation-report/en/. Accessed March 7, 2016.

4. World Health Organization. WHO statement on the first meeting of the International Health Regulations (2005) (IHR 2005) Emergency Committee on Zika virus and observed increase in neurological disorders and neonatal malformations. WHO website. http://www.who.int/mediacentre/news/ statements/2016/1st-emergency-committee-zika/en/. Published February 1, 2016. Accessed February 2, 2016.

5. Institute of Medicine (US). Committee on Emerging Microbial Threats to Health., Lederberg J, Shope RE, Oaks SC. Emerging infections: microbial threats to health in the United States. Washington, DC: National Academy Press; 1992.

6. Dick GW, Kitchen SF, Haddow AJ. Zika virus. I. Isolations and serological specificity. Trans R Soc Trop Med Hyg. 1952;46(5):509-520. http://dx.doi.org/10.1016/0035-9203(52)90042-4.

7. Duffy MR, Chen TH, Hancock WT, et al. Zika virus outbreak on Yap Island, Federated States of Micronesia. $N$ Engl J Med. 2009; 360(24):2536-2543. http://dx.doi.org/10.1056/NEJMoa0805715.

8. Cao-Lormeau VM, Roche C, Teissier A, et al. Zika virus, French Polynesia, South Pacific, 2013. Emerg Infect Dis. 2014;20(6):1085-1086. http://dx.doi.org/10.3201/eid2006.140138.

9. Schuler-Faccini L, Ribeiro EM, Feitosa IM, et al. Possible association between Zika virus infection and microcephaly - Brazil, 2015. MMWR Morb Mortal Wkly Rep. 2016;65(3):59-62. http://dx.doi.org/10.15585/ mmwr.mm6503e2.

10. Etymologia: Zika virus. Emerg Infect Dis. 2014;20(6):1090. http://dx.doi. org/10.3201/eid2006.ET2006.

11. Gubler DJ. Insects In Disease Transmission. In: Hunter GW, Strickland GT, eds. Hunter's Tropical Medicine. Vol 1. 7th ed. Philadelphia: W.B. Saunders; 1991:981-999.

12. Enfissi A, Codrington J, Roosblad J, et al. Zika virus genome from the Americas. Lancet. 2016;387(10015):227-228. http://dx.doi.org/10.1016/ S0140-6736(16)00003-9.

13. Hayes EB. Zika virus outside Africa. Emerg Infect Dis. 2009; 15(9):1347-1350. http://dx.doi.org/10.3201/eid1509.090442.

14. Hamel R, Dejarnac O, Wichit S, et al. Biology of Zika virus infection in human skin cells. J Virol. 2015;89(17):8880-8896. http://dx.doi.org/ 10.1128/JVI.00354-15.

15. Tang H, Hammack C, Ogden SC, et al. Zika virus infects human cortical neural progenitors and attenuates their growth. Cell Stem Cell. 2016;18. http://dx.doi.org/10.1016/j.stem.2016.1002.1016.

16. Martines RB, Bhatnagar J, Keating MK, et al. Notes from the field: evidence of Zika virus infection in brain and placental tissues from two congenitally infected newborns and two fetal losses - Brazil, 2015. MMWR Morb Mortal Wkly Rep. 2016;65(6):159-160. http://dx.doi.org/ 10.15585/mmwr.mm6506e1.

17. Haddow AJ, Williams MC, Woodall JP, et al. Twelve Isolations of Zika virus from Aedes (Stegomyia) africanus (Theobald) taken in and above a Uganda forest. Bull World Health Organ. 1964;31:57-69.

18. Darwish MA, Hoogstraal H, Roberts TJ, et al. A sero-epidemiological survey for certain arboviruses (Togaviridae) in Pakistan. Trans $R$ Soc Trop Med Hyg. 1983;77(4):442-445. http://dx.doi.org/10.1016/00359203(83)90106-2.

19. Kilbourn AM, Karesh WB, Wolfe ND, et al. Health evaluation of freeranging and semi-captive orangutans (Pongo pygmaeus pygmaeus) in Sabah, Malaysia. J Wildl Dis. 2003;39(1):73-83. http://dx.doi.org/ 10.7589/0090-3558-39.1.73.

20. Bogoch II, Brady OJ, Kraemer MU, et al. Anticipating the international spread of Zika virus from Brazil. Lancet. 2016;387(10016):335-336. http://dx.doi.org/10.1016/S0140-6736(16)00080-5.
21. Aubry M, Finke J, Teissier A, et al. Seroprevalence of arboviruses among blood donors in French Polynesia, 2011-2013. Int J Infect Dis. 2015;41:11-12. http://dx.doi.org/10.1016/j.ijid.2015.10.005.

22. Musso D, Nhan T, Robin E, et al. Potential for Zika virus transmission through blood transfusion demonstrated during an outbreak in French Polynesia, November 2013 to February 2014. Euro Surveill. 2014; 19(14):20761. http://dx.doi.org/10.2807/1560-7917.ES2014.19.14.20761.

23. Kilpatrick AM, Randolph SE. Drivers, dynamics, and control of emerging vector-borne zoonotic diseases. Lancet. 2012;380(9857):1946-1955. http:// dx.doi.org/10.1016/S0140-6736(12)61151-9.

24. Boorman JP, Porterfield JS. A simple technique for infection of mosquitoes with viruses; transmission of Zika virus. Trans $R$ Soc Trop Med Hyg. 1956;50(3):238-242. http://dx.doi.org/10.1016/0035-9203(56) 90029-3.

25. Li MI, Wong PS, Ng LC, et al. Oral susceptibility of Singapore Aedes (Stegomyia) aegypti (Linnaeus) to Zika virus. PLoS Negl Trop Dis. 2012; 6(8):e1792.

26. Besnard M, Lastere S, Teissier A, et al. Evidence of perinatal transmission of Zika virus, French Polynesia, December 2013 and February 2014. Euro Surveill. 2014;19(13):20751. http://dx.doi.org/ 10.2807/1560-7917.ES2014.19.13.20751.

27. Dupont-Rouzeyrol M, Biron A, O'Connor O, et al. Infectious Zika viral particles in breastmilk (letter). Lancet. 2016;387:1051. http://dx.doi.org/ 10.1016/S0140-6736(1016)00624-00623.

28. Hills SL, Russell K, Hennessey M, et al. Transmission of Zika virus through sexual contact with travelers to areas of ongoing transmission continental United States, 2016. MMWR Morb Mortal Wkly Rep. 2016;65(8):215-216. http://dx.doi.org/10.15585/mmwr.mm6508e2.

29. Oster AM, Brooks JT, Stryker JE, et al. Interim guidelines for prevention of sexual transmission of Zika virus - United States, 2016. MMWR Morb Mortal Wkly Rep. 2016;65(Early Release):1-2. doi: http://dx.doi.org/ 10.15585/mmwr.mm16505e15581er.

30. Foy BD, Kobylinski KC, Foy JLC, et al. Probable non-vector-borne transmission of Zika virus, Colorado, USA. Emerg Infect Dis. 2011; 17(5):880-882. http://dx.doi.org/10.3201/eid1705.101939.

31. Musso D, Roche C, Robin E, et al. Potential sexual transmission of Zika virus. Emerg Infect Dis. 2015;21(2):359-361. http://dx.doi.org/ 10.3201/eid2102.141363.

32. McNeil DG, Tavernise S. Zika infection transmitted by sex reported in Texas. The New York Times. http://nyti.ms/206J6vS. Published February 2, 2016. Accessed February 10, 2016.

33. Mansuy JM, Dutertre M, Mengelle C, et al. Zika virus: high infectious viral load in semen, a new sexually transmitted pathogen (letter) [published online ahead of print March 3, 2016]? Lancet Infect Dis. http:// dx.doi.org/10.1016/S1473-3099(1016)00138-00139.

34. Boadle A. Brazil reports Zika infection from blood transfusions. Reuters.com. http://www.reuters.com/article/us-health-zika-brazil-bloodidUSKCNOVD22N. Published February 4, 2016. Accessed February 13, 2016.

35. American Association of Blood Banks. Association Bulletin \#16-04: Zika, Dengue, and Chikungunya Viruses. 1 March 2016. http:/www.aabb.org/ programs/publications/bulletins/Documents/ab16-04.pdf. Accessed March 21, 2016.

36. Centers for Disease Control and Prevention. Zika Virus: Symptoms, Diagnosis, \& Treatment. http://www.cdc.gov/zika/symptoms/index.html. Version current February 3, 2016. Accessed February 12, 2016.

37. Cao-Lormeau VM, Blake A, Mons S, et al. Guillain-Barre Syndrome outbreak associated with Zika virus infection in French Polynesia: a casecontrol study [published online ahead of print February 29, 2016]. Lancet. http://dx.doi.org/10.1016/S0140-6736(1016)00562-00566.

38. Smith DW, Mackenzie J. Zika virus and Guillain-Barre syndrome: another viral cause to add to the list [published online ahead of print February 29, 2016]. http://dx.doi.org/10.1016/S0140-6736(1016)00564-X.

39. Willison HJ, Jacobs BC, van Doorn PA. Guillain-Barré Syndrome [published online ahead of print February 29, 2016]. Lancet. http://dx.doi. org/10.1016/S0140-6736(1016)00339-00331. 
40. Mecharles S, Herrmann C, Poullain P, et al. Acute myelitis due to Zika virus infection [published online ahead of print March 3, 2016]. Lancet. http://dx.doi.org/10.1016/S0140-6736(1016)00644-00649.

41. Brasil P, Pereira JP Jr, Raja Gabaglia C, et al. Zika virus infection in pregnant women in Rio de Janeiro - preliminary report [published online ahead of print March 4, 2016]. N Engl J Med. http://dx.doi.org/10.1056/ NEJMoa1602412.

42. Kleber de Oliveira W, Cortez-Escalante J, De Oliveira WTCH, et al. Increase in reported prevalence of microcephaly in infants born to women living in areas with confirmed Zika virus transmission during the first trimester of pregnancy - Brazil, 2015. MMWR Morb Mortal Wkly Rep. 2016;65(9):242-247. http://dx.doi.org/10.15585/mmwr.mm6509e2.

43. de Paula Freitas B, de Oliveira Dias JR, Prazeres J, et al. Ocular findings in infants with microcephaly associated with presumed Zika virus congenital infection in Salvador, Brazil [published online ahead of print February 9, 2016]. JAMA Ophthalmol. http://dx.doi.org/10.1001/ jamaophthalmol.2016.0267.

44. Jampol LM, Goldstein DA. Zika Virus infection and the eye [published online ahead of print February 9, 2016]. JAMA Ophthalmol. http://dx.doi. org/10.1001/jamaophthalmol.2016.0284.

45. Ventura CV, Maia M, Bravo-Filho V, Gois AL, Belfort R Jr. Zika virus in Brazil and macular atrophy in a child with microcephaly. Lancet. 2016; 387(10015):228. http://dx.doi.org/10.1016/S0140-6736(16)00006-4.

46. Meaney-Delman D, Hills SL, Williams C, et al. Zika virus infection among US pregnant travelers - August 2015-February 2016. MMWR
Morb Mortal Wkly Rep. 2016;65(8):211-214. http://dx.doi.org/10.15585/ mmwr.mm6508e1.

47. Centers for Disease Control and Prevention. Arboviral diseases, neuroinvasive and non-neuroinvasive - 2015 Case Definition 21 January 2016. http://wwwn.cdc.gov/nndss/conditions/arboviral-diseasesneuroinvasive-and-non-neuroinvasive/case-definition/2015/. Accessed February 12, 2016.

48. Centers for Disease Control and Prevention. Revised diagnostic testing for Zika, chikungunya, and dengue viruses in US. Public Health Lab. http://www. cdc.gov/zika/pdfs/denvchikvzikv-testing-algorithm.pdf. Published February 7, 2016. Accessed February 12, 2016.

49. Centers for Disease Control and Prevention. Zika virus: diagnostic testing. http://www.cdc.gov/zika/hc-providers/diagnostic.html. Version current February 11, 2016. Accessed February 12, 2016.

50. Oduyebo T, Petersen EE, Rasmussen SA, et al. Update: interim guidelines for health care providers caring for pregnant women and women of reproductive age with possible Zika virus exposure - United States, 2016. MMWR Morb Mortal Wkly Rep. 2016;65(Early Release):1-6. doi: http://dx.doi.org/10.15585/mmwr.mm16505e15582er.

51. Centers for Disease Control and Prevention. Zika virus: clinical evaluation \& disease. http://www.cdc.gov/zika/hc-providers/clinicalevaluation.html. Version current February 5, 2016. Accessed February 12, 2016.

52. Centers for Disease Control and Prevention. Zika virus: prevention. http:// www.cdc.gov/zika/prevention/index.html. Version current February 5, 2016. Accessed February 12, 2016. 